\title{
MT 10,38 JA LK 14,27 SAJANDEID PÜSINUD KÜSITAV TÕLGE
}

\author{
Peeter Roosimaa \\ Tartu Ülikool
}

\begin{abstract}
Kokkuvõte. Artikkel käsitleb Uue Testamendi eesti keelde tõlkimise probleeme. Paralleelkirjakohtades Mt 10,38 ja Lk 14,27 on Jeesuse ütlus, mis koosneb kolmest osalausest. Neist esimene ja viimane on eitavad, kuid eestikeelses tõlkes on eitatud ka teist osalauset. Selline lisaeitus leidub juba 1686. aastal ilmunud „Wastses Testamendis". Uue Testamendi esimesed eestikeelsed tõlked on teinud saksa soost pastorid, kellel oli raskusi eituste edasiandmisel saksa keele omast erineva lausestruktuuriga eesti keeles. Kasutades aastatest 1680-1705 pärinevate tõlkekäsikirjade trükis avaldatud tekste, on artiklis vaatluse alla võetud valik eitusi sisaldavaid Luuka evangeeliumi salme. Siinne uurimus lubab oletada, et Mt 10,38 ja Lk 14,27 tekstides oleva lisaeituse puhul on tegemist tõlkeeksitusega, mis on hilisemate redigeerimiste ja osalt uuesti tõlkimiste käigus jäänud märkamata.
\end{abstract}

Märksõnad: Uus Testament, piiblitõlge, eituste tõlkimine, Pilistvere käsikiri

DOI: http://dx.doi.org/10.12697/jeful.2013.4.3.09

\section{Sissejuhatus}

Siinne artikkel käsitleb Piibli, täpsemalt Uue Testamendi eesti keelde tõlkimise probleeme. Keskendun kahele eitust sisaldavale, omavahel pärimuslikult seotud tekstile, nimelt Mt 10,38 ja Lk 14,27, mille tõlge on küsitav, kuid mille põhiline tõlkekuju on alates Uue Testamendi esimestest trükkidest säilinud praeguseni.

Pärast lõunaeestikeelse „Wastse Testamendi” ilmumist 1686. aastal ja Uue Testamendi ilmumist 1715. aastal on Uut Testamenti korduvalt redigeeritud ning vähemalt osalt uuesti tõlgitud ja parandatud. ${ }^{1}$ Niisiis on ootuspärane, et Uue Testamendi eri redaktsioonidest leiame hulgaliselt erinevate tõlkevariantidega tekstiosi. Toon näiteks Mt 1,18.

1 Vt nt eestikeelsete piiblite bibliograafia nimistut (Paul 1999: 839-846). 
WT $1686^{2}$ : Ent JEsusse Kristusse Sündiminne olli ni: Kui Maria temmä Emma Joseppil olli errakichlatu/ enne kui nemmä kokko tulliwa/saije temmä rasse löitus pöhast Waimust.

UT 1715: Agga JEsusse Kristusse Sündminne olli ninda: Kui Maria temma Emma Joseppile kihlatud olli/ ennego nemmad kokko saiwad/ leieti tedda käima pääl ollewa Pühhast Waimust.

UT 1912: Aga Jeesuse Kristuse sündimine oli nõnda: Tema ema Maarja oli Joosepiga kihlatud ja, enne kui ta koju wiidi, tuli awalikuks, et tema Pühast Waimust käima peal oli.

SP 1939: Aga Jeesuse Kristuse sündimine oli nõnda: Kui tema ema Maarja oli Joosepiga kihlatud, leiti ta, ennegu nad kokku said, käima peal olewat Pühast Waimust.

P 1968: Aga Jeesuse Kristuse sündimine oli nõnda: kui ta ema Maarja oli kihlatud Joosepiga, siis ta leiti enne nende kokkusaamist käimapeal olevat Pühast Vaimust.

P 1997: Jeesuse Kristuse sündimisega oli aga nõnda. Tema ema Maarja, kes oli Joosepiga kihlatud, leidis enne enda kojuviimist, et ta ootab Pühast Vaimust last.

Nende näidete puhul on põhiküsimuseks, kes taipas, et Maarja ootab last: kas Maarja ise (P 1997) või teised inimesed, nt Naatsareti elanikud (ülejäänud näited). Lisandub küsimus, kuidas Joosep asjast teada sai. Vastused neile küsimustele aitaksid mõista Joosepi sugulaste suhtumist nii Maarjasse kui ka tema pojasse.

Teisalt on ka tekstiosi, mille tõlge on küll küsitav, kuid mis on oma põhilise kuju säilitanud praeguseni. Järgnevalt vaatlen Mt 10,38 ja Lk 14,27 tekste. ${ }^{3}$ Samuti toon eitusega lausete tõlkimise raskuste kohta Luuka evangeeliumist näiteid, mis illustreerivad väidet, et Pilistvere parandustes on eituste kasutamisel näha poolikuid lahendusi (Reila 2007: 144).

2 Siin ja edaspidi on kasutatud lühendeid, kus täht või tähed näitavad, millise teosega on tegemist (P - Piibel; SP - Suur Piibel; UT - Uus Testament; WT - Wastne Testament; $\mathrm{Lu}$ - Martin Lutheri tõlge saksa keelde), järgnev aastaarv osutab aga trükis ilmumise aastale. Kasutatud väljaannete bibliograafilised andmed on toodud artikli lõpus. Piiblitekstide osade järgnevad esiletõsted on teinud artikli autor.

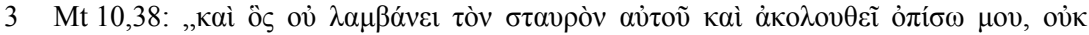

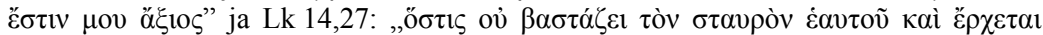

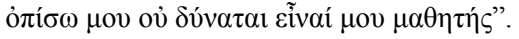




\section{Mt 10,38 ja Lk 14,27 teksti tähendus}

Mt 10,38 ja Lk 14,27 on esmapilgul üsna lihtsad, ometi võivad ka sellised tekstid sisaldada probleeme. Kuidas on eri tõlkijad neid kirjakohti tõlgendanud? Selle mõistmiseks tutvusin paljude Uue Testamendi väljaannetes ja kommentaarkirjanduses leiduvate erikeelsete (saksa, inglise, vene, soome) tõlgetega (nt Schweizer 1981: $161 \mathrm{jj}$, Grundmann 1975: 299 jj, Schlatter 1979: 315, Barklay 1968: 215 jj). Kõigis neis on vaadeldavate kirjakohtade tõlkesisu järgmine:

Mt 10,38. Ja kes oma risti enesele ei võta ja järgib mind, see ei ole mind väärt;

Lk 14,27. Ja kes ei kanna oma risti ja tuleb minu järel, see ei või olla minu jünger.

Mõte on selles, et üksnes Jeesuse või kristlastega kaasaskäimine või n-ö kaasajooksikuks olemine ei tee inimest veel Jeesuse õpilaseks ega kristlaseks. Vaja on väga põhimõttelist ja olemuslikku elumuutust, mida Jeesus nimetab oma risti endale võtmiseks, mis tähendab valmisolekut ka märtrisurmaks.

Eesti keelde on neid kirjakohti tõlgitud aga pisut teisiti. Nimelt on eestikeelsetes tõlgetes üks eitus rohkem. P 1997 esitab samad kirjakohad nii:

Mt 10,38. Ja kes ei võta oma risti ega järgne mulle, see ei ole mind väärt;

Lk 14,27. Kes ei kanna oma risti ega käi minu järel, see ei või olla minu jünger.

Niisuguse tõlke mõte on selles, et inimene, kes ei võta oma risti ega järgi Jeesust, ei ole teda väärt või vastavalt ei ole Jeesuse õpilane. Aga on ju niigi selge, et see, kes ei järgne Jeesusele, olgu siis ristiga või ilma, ei ole Jeesusega seotud, ei ole tema õpilane. Nii on Jeesuse mõte kaasajooksikutest läinud eestikeelses tõlkes kaduma.

Siiski võiks topelteitusel olla mõte parallelismi puhul, samuti selgitava ja (nn kai-epexegeticus'e) puhul. Parallelism toob esile ühe ja sama põhihoiaku kaks külge. Selle kohaselt näitavad nii Jeesuse järel käimine kui ka enda risti kandmine sama põhihoiakut: kristlaseks olekut. Järelikult võiks see nii olla ka eituste puhul. Kes ei kanna oma risti, ei ole Jeesuse järgija. Eelnevaga sarnaneb selgitava $j a$ abil vormistatud kai-epexegeticus'ega lause. Sel puhul ühendab kaht osalauset sidesõna ja (= kreeka keeles $\mathrm{kai}$ ) ning kai'le järgnev osalause selgitab eelmise osalause mõtet. Niisugust kai'd võiks tõlkida fraasidega $j a$ nimelt või see tähendab. Seega võiks Mt 10,38 tõlge olla „Ja kes ei 
võta oma risti, see tähendab, et ta ei järgne mulle, see ei ole mind väärt". Olgu öeldud, et kuigi kreekakeelne algtekst eituse kujul sellele tõlgendusele otsest vormilist alust ei anna, võidi tõlkimisel siiski silmas pidada kai-epexegeticus'e, eelkõige aga parallelismi kasutamise võimalust. Neid stiilivõtteid kasutasid Piibli autorid sageli (Reiser 2001: 156, 244).

\section{Mt 10,38 ja Lk 14,27 probleemse tõlke püsimine}

Kui vaadata Uue Testamendi eestikeelse tõlke ajaloos tagasi, võib näha, et juba 1686. aastal esimesena välja antud „Wastses Testamendis” on kirjas:

Mt 10,38. Nink kä omma Risti ei wötta henne pähle/ nink ei tulle minno perrä/ se ei olle mitte minno währt;

Lk 14,27. Nink kä omma Risti ei kanna/ nink ei tulle minno perrä/ se ei woi minno Jünger olla.

WT 1686 eeskujul on Uue Testamendi esimeses põhjaeestikeelses tõlkes (UT 1715):

Mt 10,38. Ja ke ei wotta omma Rist/ ja ei tulle minno järrele/ se ep olle minno mitte wäärt;

Lk 14,27. Ning ke omma Risti ei kanna/ ja minno järrele ei tulle/ se ei woi minno Jünger olla. ${ }^{4}$

Selline lisaeitusega tõlkevariant on säilinud nii hilisemates ,Wastse Testamendi" kui ka Uue Testamendi redaktsioonides ja tõlgetes, sealhulgas isegi Jaan Bergmanni põhjalikult redigeeritud ja kohati uuesti tõlgitud Uue Testamendi 1912. aasta proovitrükis (UT 1912), samuti eestikeelse Piibli 200. aasta juubeli tähistamiseks välja antud Uku Masingu ja Harald Wilhelm Põllu põhjalikult redigeeritud ja traditsioonilistest väljaannetest küllaltki erineva keelega Suures Piiblis (SP 1939). Lisaeitus sisaldub ka palju kasutatavas 1968. aasta Piiblis (P 1968) ja selle redigeeritud väljaannetes, samuti Toomas Pauli ja Uku Masingu uues tõlkes (UT 1989), mis oli omakorda alustekst 1997. aasta Piibli (P 1997) Uue Testamendi redigeerimisel (Bärenson 1998). Niisiis on Mt 10,38 ja Lk 14,38 tõlkekuju muutunud lausa traditsiooniks, mis on püsinud sajandeid.

4 UT 1715 tõlke üheks eeskujutekstiks oli WT 1686 (Roosimaa 2004: 39). 


\section{Mt 10,38 ja Lk 14,27 esimestest eestikeelsetest tõlgetest}

Uue Testamendi esimese eestikeelse trükivalgust näinud tõlke, 1686. aastal ilmunud „Wastse Testamendi” koostas Toomas Pauli uurimuse kohaselt ilmselt küll isa kaasabil noor Adrian Virginius, samuti aitas kaasa Johann Nicolaus Hardung (Paul 1999: 328). Arvamust Adriani rolli kohta tõlkimisel võiks toetada seegi, et kuigi tema isa oli juba varem Piiblit tartu keelde tõlkinud, maksti tõlke eest Emanuel Regeri arveraamatu järgi ainult Adrianile (Tafenau 2011a: 57, vt ka Tafenau 2011c: 13-14). Peatudes Adrian Virginiuse elulool, avaldab Kai Tafenau kahtlust, kas Adrian Virginius oli tõesti „Wastse Testamendi” tõlkija (Tafenau 2009: 851). Tafenau ütleb oma dissertatsiooni kokkuvõttes, et Andreas Virginius oli tartu keelde tõlkinud Uue Testamendi ja osa Vanast Testamendist. Tema pojast Adrian Virginiusest sai 1680. aastatel peamine tartukeelsete raamatute trükki toimetaja (Tafenau 2011c: 230). Ilmselt võib nõustuda Tafenau tõdemusega, et ,[1]õplikku tõde selles küsimuses pole ilmselt enam võimalik välja selgitada, võib vaid nentida, et piir tõlkimise ja toimetamise vahel on ka teiste XVII sajandi lõpust ja XVIII sajandi algusest pärinevate tõlgete puhul ebamäärane" (Tafenau 2009: 852). Eelöeldust lähtudes arvestan, et WT 1686 tõlkijad olid Virginiused. Oma tõlke alusena kasutasid nad Martin Lutheri saksa tõlget, abiks oli ka kreekakeelne tekst (Roosimaa 2003: 179, 184).

Vaadeldavates kirjakohtades on Lutheri tõlkes $\left(\mathrm{Lu} 1670^{5}\right)$ öeldud:

Mt 10,38. Und wer nicht sein Creutz auff sich nimbt/ und folget mir nach/ der ist mein nicht werd;

Lk 14,27. Und wer nicht sein Creutz träget/ und mir nachfolget/ der kan nicht mein Jünger seyn.

Nagu näha, puudub Lutheri tõlkes nii Mt 10,38 kui ka Lk 14,27 teisest osalausest eitus. Mõte on selles, et kes küll järgib Jeesust, kuid ei võta enesele oma risti või ei kanna oma risti, ei ole Jeesust väärt või ei saa olla tema jünger.

Kui Virginiused olid otsustanud tõlkida Lutherist erinevalt, võiks oodata, et nad leidsid selleks tuge kreekakeelsest tekstist. Kuid kreekakeelse Uue Testamendi tekstikriitiline aparaat ei paku neile kirjakohtadele mingeid muid variante (vt Nestle-Aland ${ }^{27} 1993: 26,210$ ).

$\mathrm{X}$ vana kirjakeele päeval juhtis emeriitprofessor Tiit-Rein Viitso, kes oli käsitletavat teemat teades kontrollinud mõlemat kirjakohta,

5 Valitud on üks võimalikest tõlkijatel kasutada olnud tekstidest. Sellest ajast pärit Lutheri tõlke eri väljaanded on sisuliselt samad, erinevusi esineb põhiliselt ortograafias ja interpunktsioonis (Roosimaa 2003: 173). 
tähelepanu asjaolule, et 17. sajandil oli niisugune lisaeitus olnud kasutusel ka lätikeelses Uues Testamendis, ${ }^{6}$ ning küsis, kas sellisel tõlkel ei võinud olla siiski mingit sügavamat mõtet, mis lähtunuks Jeesuse ütluse kontekstist. $^{7}$

Jeesuse ütluse kontekst toetab siiski pigem vastupidist arusaama, s.t üht eitust. Luuka evangeeliumis pöördub Jeesus enda järel käivate inimeste poole, et juhtida nende tähelepanu vajadusele teda tõsiselt järgida. Matteuse evangeeliumis on tegu katkendiga Jeesuse läkitusjutlusest. Mõlemal juhul on ühiseks läbivaks mõtteks radikaalse pühendumise ja otsustamise nõue. Selle kohaselt võib Kristuse misjoniülesande täitmine vallandada väga tõsiseid konflikte, ka selliseid, kus vastanduvad Kristusele pühendumine ja suhted teiste inimestega, valmisolek Kristuse nimel oma elu ohverdada ja kristlastega lihtsalt kaasaskäimine. Kuigi vaadeldava ütluse sõnastus on praeguse tõlke kohaselt hästi ladus ja selle mõte on täiesti arusaadav - sellisel inimesel ei ole Kristuselt oodata mingit tunnustust -, siis kaasajooksiku mõiste (see, kes järgneb Kristusele, aga ei võta oma risti kanda) toob ütluse radikaalse sisu veelgi paremini esile.

Pärast lähtetekstidega tutvumist näib kõige tõepärasem seletus olevat, et Virginiused on tõlkega (tõlgendusega) lihtsalt eksinud, aga välistada ei saa ka seda, et neid on mõjutanud soov kasutada parallelismi või kai-epexegeticus't. Teksti hilisemad redigeerijad aga ei ole nii väikest vormilist erinevust enam tähele pannud, sest tõlge on tundunud loogiline. Järgnevalt püüan jõuda selgusele, mis võis Virginiuste eksituse põhjustada.

\section{Võrdlus Pilistvere käsikirjadega}

Teadaolevalt püüdis hulk vaimulikke 17. sajandil Uut Testamenti eesti keelde tõlkida, kuid trükivalmis tekstini ei jõutud. Edu saabus siis, kui Rootsi kuningas usaldas lõunaeestikeelse „Wastse Testamendi” väljaandmist korraldama Liivimaa kindralsuperintendendi Johann Fischeri (Paul 1999: 314). Samuti usaldati talle Uue Testamendi põhjaeestikeelsete tõlgete revideerimise korraldamine ja trükkimise ettevalmistamine (Paul 1999: 361-362). Seetõttu korraldas Fischer 1686. aastal Liepas (Lindenhofis) ja 1687. aastal Pilistveres nn piiblikonverentsid, kus toimetati valmis tõlkeid ja tõlgiti uusi tekstiosi. ${ }^{8}$

6 Kahtlemata oleks õige uurida eesti- ja lätikeelsete tõlgete võimalikke seoseid, kuid siinse uurimuse käsitlusulatusest jääb selle küsimuse põhjalikum analüüs paraku välja.

7 Tiit-Rein Viitso suuline kommentaar 12. novembril 2010 Tartu Ülikoolis X vana kirjakeele päeval.

8 Konverentside kohta vt lähemalt Paul 1999: 364-371. 
Piiblikonverentsidel tehtud tööle heidavad valgust käsikirjad, mille tekstid on avaldatud Kristiina Rossi koostatud teoses „Põhjaeestikeelsed Uue Testamendi tõlked 1680-1705" (Ross 2007). Teoses on toodud Luuka evangeeliumi ja apostlite tegude raamatu neli tõlget, mis pärinevad ajavahemikul 1680-1705 kirja pandud kolmest käsikirjast. Kahes esimeses veerus esitatud tõlked tuginevad ühele ja samale põhjalikult toimetatud käsikirjale või käsikirjade kogumile, mille kallal oli töötatud 1687. aasta Pilistvere piiblikonverentsil. Esimeses veerus olev Pilistvere käsikirja algversioon aastatest $1680-1687$ on eri fragmentidest pärit tekst niisugusena, nagu see oli eri aegadel algselt kirja pandud. Teises veerus olev Pilistvere käsikirja lõppversioon aastast 1687 kajastab Pilistvere piiblikonverentsil tehtud toimetamistööd. ${ }^{9}$ Kolmandas veerus on toodud Müncheni käsikiri, mis sisaldab 1694. aastal tollase Põltsamaa abiõpetaja Johann Hartmann Creidiuse kirja pandud tõlkeversiooni. Neljandas veerus oleva 1705. aastast pärineva Stockholmi käsikirja teksti üleskirjutajaks peetakse Pilistvere õpetajat Johann Daniel Bertholdi. Kaks viimast käsikirja on nime saanud nende säilitamise koha järgi. (Ross 2007: 5-6) Siinses käsitluses ei ole käsikirjade autorsuse küsimusse lähemalt süvenetud. Olgu vaid kokkuvõtvalt öeldud, et suure tõenäosusega oli Pilistveres toimetamisele tulnud tekst „Pil alg” Heinrich Göseken vanema käsikirja ärakiri, mida ümberkirjutaja oli kohati täiendanud-parandanud ja ühtlustanud (Tafenau 2006: 266).

Nagu eespool öeldud, on Mt 10,38 ja Lk 14,27 omavahel pärimuslikult seotud ja nende kontekst on võrreldav. WT 1686-s on need salmid tõlgitud ühel ja samal põhimõttel. Seepärast piirdun järgnevas eituse tõlke probleemi analüüsis üksnes Luuka evangeeliumi kirjakoha käsitlemisega.

Lk 14,27 on käsikirjas „Pil alg” tõlgitud järgmiselt:

Ninck ke mitte omma willizuße kandap, ninck münno ierrel keit, Temma woip mitte münno Sullane olla.

Paistab, et siin on tegemist toortõlkega saksa keelest. Kirjakoht koosneb kolmest osalausest, kusjuures nii esimeses kui ka kolmandas osalauses väljendatakse eitust eitussõnaga mitte. Öeldisverbi lõpp vastab mõlemas osalauses ainsuse kolmanda pöörde lõpule kandap, woip. Teises osalauses eitussõna puudub, kuid öeldisverbi lõpp varieerub, seal oleva verbi keit lõpp vastab ainsuse teisele pöördele. Niisugust teise ja kolmanda pöörde lõpu varieeruvust võib käsikirjast „Pil alg” leida veelgi. Näiteks on ainsuse teise pöörde lõpu asemel kolmanda pöörde lõpp Lk 12,58: „Kuß Sinna agkas sünno lehhimeße

9 Selle käsikirja versioonide lühenditena kasutan vastavalt Pil alg ja Pil lópp. 
kaa kochto ette keip, ...”, samuti Lk 14,13: „Erranis kus Sinna öhhe Piddo piddap, ...”. Ainsuse kolmanda pöörde lõpu asemel on aga teise pöörde lõpp Lk 9,26: „Ke aggas hend münno ninck münno Sanna perrast hebbendat, Temma perrast saht hend kahß hebbendama Jummala Poick, ...”; Lk 14,26: „Kus kekit münno jure tullet ninck wehat mitte temma Jßa, Emma, Naine, Lapset, wendat, Sößarat, ninck wehl pehlekit omma Ello, Temma woit mitte münno Sullane olla".

Käsikirjast „Pil lõpp” on need probleemid enamasti kõrvaldatud. Ilmselt kasutati selleks ka juba ilmunud WT 1686 teksti abi, mida võiks järeldada sellest, et käsikirjas „Pil lõpp” leidub juba WT 1686 sarnaselt lisaeitus: „Ninck ke omma Riste ep kanda, ninck münno ierrel ep kei, Se ep woi mitte münno jünger olla.” WT 1686 märgatavat mõju käsikirjale „Pil lõpp” on täheldatud ka teistes uurimustes. Näiteks tuleb see esile Heiki Reila Uue Testamendi tõlgete omavahelise kattuvuse uurimusest (Reila 2007: 148-150). Kai Tafenau juhib tähelepanu juba 1686. aasta Liepa konverentsil tehtud parandustele: „WT kasutamise poolt räägivad vahelehtedele ja tõlke kõrvale kirjutatud kommentaarid, mis kattuvad WT omadega ..." (Tafenau 2006: 267; vt ka ib.: 268, 270). Olgu siin nimetatud, et WT 1686 üks tõlkijaid Adrian Virginius osales samuti 1687. aasta Pilistvere piiblikonverentsil (Paul 1999: 364, 367), mis kahtlemata soodustas WT 1686 eeskujuna kasutamist.

Käsikirjaga „Pil lõpp” sarnane lisaeitus kordub ka Müncheni ja Stockholmi käsikirjas. Müncheni käsikirjast võib lugeda: „Ning ke omma Risti ei kanna, ning minno järrele ei tulle; ei woi minno jünger olla”, Stockholmi käsikirjast aga: „Ning ke omma Risti ei kanna, ning minno järrele ei tulle; ei woi minno Jünger olla". ${ }^{10}$

\section{Eri tekstide omavaheline seos}

Et hinnata Lk 14,27 tõlketekstide omavahelist sõltuvust või sõltumatust, võtan vaatluse alla Lk 14,25-35, mille kohta olen koostanud sünoptilise tabeli, kus on toodud materjal Pilistvere käsikirja alg- ja lõppversioonist, WT 1686-st ja Lu 1670-st ning Blaeu 1633 kreekakeelsest tekstist. ${ }^{11}$ Võrdleval analüüsil pööran tähelepanu järgmistele asjaoludele.

10 Järgnevast käsitlusest jäävad Müncheni ja Stockholmi käsikiri kõrvale.

11 Suure tõenäosusega oli Adrian Virginiusel kasutada Madalmaade kirjastaja ja trükkali Guilielmus Blaeu 1633. aastal välja antud kreekakeelne tekst (vt Roosimaa 2003: 173). 
1. Milline on lause struktuur? Kas lauses on vormi või sisu eripärasid, mis võimaldaksid järeldada, kas tõlge pärineb kreeka- või saksakeelsest tekstist?

2. Kas on mingeid tekstierisusi, mis viitaksid võrreldavate tekstide omavahelisele sõltuvusele või sõltumatusele?

3. Kas vastavuses olevad sõnad langevad tähenduse ja vormi poolest kokku?

4. Kas vastavuses olevad laused langevad struktuuri poolest kokku või on lauseliikmete kasutuses ja osalausete paigutuses erinevusi?

5. Kas pöördsõnade isikuvormi valikul on erinevusi?

6. Kas leidub spetsiifilisi saksa keelest põhjustatud iseärasusi?

7. Kas saab teha mingeid muid tähelepanekuid, mis võiksid viidata kasutatud alustekstile?

Artiklis ei ole esitatud kogu tabel, vaid toodud on üksnes ilmekamad näited. Et omavahelises vastavuses olevaid sõnu, fraase, osalauseid vmt muust tekstist esile tõsta, on kasutatud mitmesuguseid allakriipsutusi.

Sünoptilisest tabelist võib kergesti näha, et eesti tõlgete lausestruktuur järgib Lutheri teksti oma. Eriti silmatorkav on see kohtades, kus kreeka keeles on kasutatud verbide käändelisi vorme sisaldavaid lausekonstruktsioone. $^{12}$

Tabelis 1 on näide Lk 14,25 ja Lk 14,28 kohta.

Tabel 1. Lk 14,25; Lk 14,28

\begin{tabular}{|c|c|c|c|c|}
\hline Pil alg & Pil lõpp & WT 1686 & Lu 1670 & Blaeu 1633 \\
\hline $\begin{array}{l}\text { III. Nink } \\
\underline{\underline{\text { tahß}} \text { lex }} \\
\text { pallio Rahwa } \\
\text { Temma kaas, } \\
\text { ninck } \\
\underline{\text { Temma }} \\
\underline{\text { kehndas }} \\
\underline{\text { hend nende }} \\
\text { pohl ninck } \\
\text { pajatas: }\end{array}$ & $\begin{array}{l}\text { III. pallio } \\
\text { Rahwas } \\
\text { aggas lex } \\
\text { Temma kaa, } \\
\text { ninck } \\
\underline{\text { Temma }} \\
\text { pöhras } \\
\underline{\text { endast nende }} \\
\text { pohle ninck } \\
\text { pajatas: }\end{array}$ & $\begin{array}{l}\text { 25. Ent paljo } \\
\text { Rachwast } \\
\text { lätz } \\
\text { temmaga: } \\
\text { Nink temmä } \\
\underline{\text { kähnd hendä }} \\
\underline{\text { ümbre/ nink }} \\
\underline{\text { üttel neide }} \\
\underline{\text { wasta: }}\end{array}$ & $\begin{array}{l}\text { 25. ES gieng } \\
\text { aber viel } \\
\text { Volcks mit } \\
\text { ihm/ und er } \\
\text { wandte sich/ } \\
\underline{\text { und sprach }} \\
\underline{\text { zu ihnen: }}\end{array}$ & 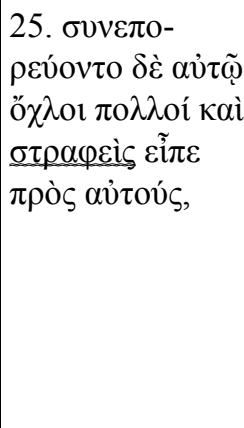 \\
\hline
\end{tabular}

12 Selle kohta, et WT 1686 tõlkimise alustekstiks on olnud Martin Lutheri tõlge, vt lähemalt Roosimaa 2003: 184. 


\begin{tabular}{|c|c|c|c|c|}
\hline Pil alg & Pil lõpp & WT 1686 & Lu 1670 & Blaeu 1633 \\
\hline $\begin{array}{l}\text { 28. Ke agkas } \\
\text { on teiie sehs, } \\
\text { ke öhe Torni } \\
\underline{\text { tahhat ülles }} \\
\underline{\text { ehhitama, }} \\
\underline{\text { ninck enne }} \\
\underline{\text { mitt arwo }} \\
\underline{\text { töht, kas }} \\
\text { temmal ni } \\
\text { pallio warra } \\
\text { on, sedda } \\
\text { tehha. }\end{array}$ & $\begin{array}{l}\text { 28. Sest Kes } \\
\text { on teiie sehs, } \\
\text { ke öhe Torni } \\
\underline{\text { tahhap ülles }} \\
\underline{\text { tehha nink ep }} \\
\text { isto enne } \\
\underline{\text { ninck ep }} \\
\underline{\text { arwa enne }} \\
\underline{\text { sedda kullo, }} \\
\text { kas temmal } \\
\text { on ni paljo, } \\
\text { et temma } \\
\text { woix sedda } \\
\text { otza sahta }\end{array}$ & $\begin{array}{l}\text { 28. Sest kes } \\
\text { om teije } \\
\text { sean/ kä } \\
\text { tahab Torni } \\
\underline{\text { ülles tettä/ }} \\
\text { nink ei isto } \\
\text { enne/ nink ei } \\
\underline{\text { arwa erra }} \\
\underline{\text { sedda }} \\
\underline{\text { Hukkust/ kas }} \\
\text { temmal om/ } \\
\text { sedda } \\
\text { löppetada? }\end{array}$ & $\begin{array}{l}\text { 28. Wer ist } \\
\text { aber unter } \\
\text { euch/ der } \\
\text { einen Thurn } \\
\text { bauen wil/ } \\
\text { und sitzet } \\
\text { nicht zuvor/ } \\
\underline{\text { und }} \\
\underline{\text { überschlägt }} \\
\underline{\text { die Kost/ ob }} \\
\text { ers habe } \\
\text { hinauszufüh } \\
\text { ren? }\end{array}$ & 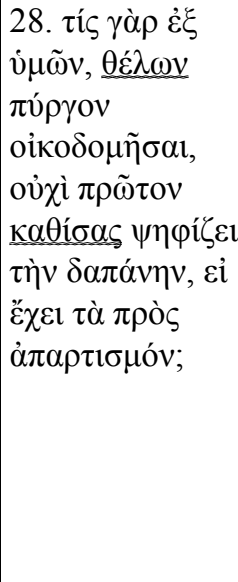 \\
\hline
\end{tabular}

Siin on Lutheri tõlkes kreekakeelsete partitsiipide asemel kasutatud

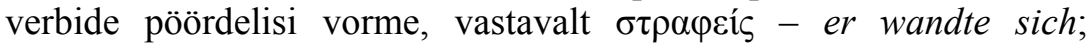
$\theta \varepsilon ́ \lambda \omega v$ - der ... will; $\kappa \alpha \theta i ́ \sigma \alpha \varsigma$ - sitzt. Selle tõttu on muutunud ka lausete sruktuur. Eesti tõlked lähtuvad omakorda Lutheri tõlke lauseehitusest, mis on ka mõistetav, sest saksa keele lauseehitus on eesti omale palju lähedasem kui kreeka keele lauseehitus. Eriti võõras on eesti keelele verbi käändeliste vormide kasutus, mis esineb aga kreekakeelsetes lausetes väga sageli. Lutheri teksti ja eesti tõlke sõnajärje mõningane erinevus on tihti tingitud sellest, et eessõnade asemel kasutatakse eesti keeles enamasti käändelõppe või tagasõnu.

Veel on tabelist näha, et tõlkes leidub alustekstist ka kõrvalekaldeid. Nii on käsikirjas „Pil alg” salmis 25 (III) sõna $\operatorname{tah} \beta$, millel Lutheri tekstis vaste puudub; fraas und sprach zu ihnen on aga tõlgitud lihtsalt ninck pajatas.

Salmis 28 on fraas und überschlägt die Kost tõlgitud ninck enne mitt arwo töht. Siin on küsimuseks sõna töht vorm. Sama sõne on selle peatüki 12. salmis ühemõtteliselt tõlgendatav ainsuse teise pöörde vormina (teed), vaadeldavas salmis oli aga ilmselt mõeldud ainsuse kolmandat pööret väljendverbist arvu tegema ('arvet pidama'). Tõlkimata on jäänud fraas und sitzet nicht zuvor.

Lk 14,26 puhul (tabel 2) on käsikirjas „Pil alg” sõna-sõnalt tõlgitud Lutheri tekst. Seejuures on saksa sõna Jünger tõlgitud eesti keelde sõnaga Sullane. Ka WT 1686 tekst on tõlgitud Lutheri järgi, kuid tõlkija on kasutanud abiks veel kreekakeelset teksti ja lisanud selle eeskujul sidesõnad nink. Seejuures on sõna Jünger saksakeelsest tekstist tõlkimata üle võetud. Käsikirjas „Pil lõpp” on samuti muudatusena 
lisatud sidesõnad nink, kasutades selleks lühendit $n$. Sõna Sullane on asendatud sõnaga Jünger.

Tabel 2. Lk 14,26

\begin{tabular}{|c|c|c|c|c|}
\hline Pil alg & Pil lõpp & WT 1686 & Lu 1670 & Blaeu 1633 \\
\hline 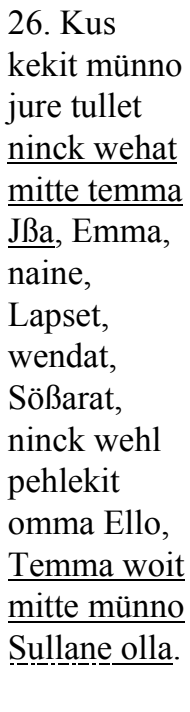 & $\begin{array}{l}\text { 26. Kus } \\
\text { kekit münno } \\
\text { jure tullep } \\
\text { ninck ep } \\
\text { wihha mitte } \\
\text { omma Jßa, } \\
\text { n. Emma, } \underline{\text { n. }} \\
\text { Naise, } \underline{\underline{n} .} \\
\text { Lapse, } \underline{\underline{n}} . \\
\text { wennat, } \underline{\underline{n}} . \\
\text { Öddet, ninck } \\
\text { wehl } \\
\text { pehlekit } \\
\text { omma Ello, } \\
\text { Se ep woi } \\
\text { mitte münno } \\
\text { Jünger olla. }\end{array}$ & 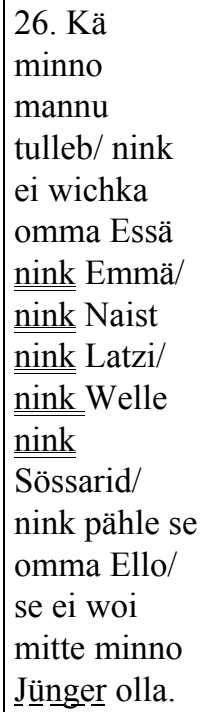 & $\begin{array}{l}\text { 26. So } \\
\text { jemand zu } \\
\text { mir kombt } \\
\text { und hasset } \\
\text { nicht seinen } \\
\underline{\text { Vatter/ }} \\
\text { Mutter/ } \\
\text { Weib/ Kind/ } \\
\text { Bruder/ } \\
\text { Schwester/ } \\
\text { auch darzu } \\
\text { sein eigen } \\
\text { Leben/ der } \\
\text { kan nicht } \\
\underline{\text { mein Jünger }} \\
\underline{\text { seyn. }}\end{array}$ & 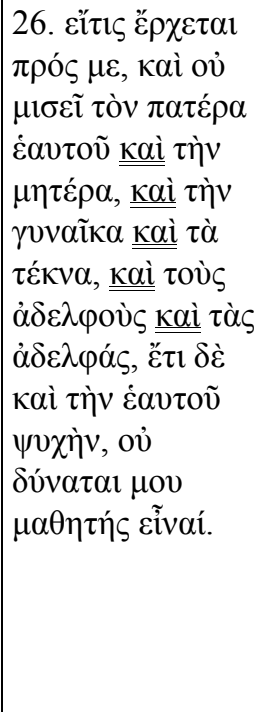 \\
\hline
\end{tabular}

Kui Lk 14,30 (tabel 3) on käsikirjas „Pil alg” Lutheri teksti fraas fieng an zu bauen tõlgitud sõnadega halgkas ehhitada, siis käsikirja „Pil lõpp" on WT 1686 tekstist lisatud sõna Torni (WT 1686 teksti on Torni jõudnud ilmselt 28. salmi eeskujul, nagu võiks viidata ka sulgude kasutamine 30. salmis) ja verb ehhitada on asendatud verbiga teggema. Sõna Mensch on aga Pilistvere käsikirjadest lihtsalt välja jäetud.

Tabel 3. Lk 14,30

\begin{tabular}{|c|c|c|c|c|}
\hline Pil alg & Pil lõpp & WT 1686 & Lu 1670 & Blaeu 1633 \\
\hline $\begin{array}{l}30 . \text { Ninck } \\
\text { ütlewat: } \\
\text { nesinnane } \\
\text { halgkas } \\
\text { ehhitada, } \\
\text { ninck woip } \\
\text { mitte eddes } \\
\text { sahma. }\end{array}$ & $\begin{array}{l}\text { 30. Ninck } \\
\text { ütlewat: Sesin- } \\
\text { nane hakkis } \\
\text { Torni teggema, } \\
\text { ninck ep woinut } \\
\text { mitte sedda otza } \\
\text { sahta. }\end{array}$ & \begin{tabular}{|l|} 
30. Nink \\
ütlema: \\
Sesinane \\
Mehs naksi \\
$\underline{\text { (Torni) }}$ ülles \\
$\underline{\text { teggemä/ nink }}$ \\
es jouwwa \\
löppetada.
\end{tabular} & $\begin{array}{l}\text { 30. Und } \\
\text { sagen: Dieser } \\
\text { Mensch fieng } \\
\text { an zu bauen/ } \\
\text { und kans } \\
\text { nicht } \\
\text { hinausführen. }\end{array}$ & 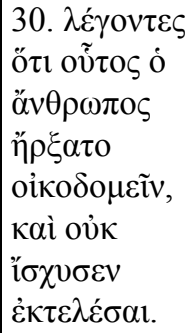 \\
\hline
\end{tabular}


Lk 14,32 (tabel 4) on väljend Wo nicht käsikirjas „Pil alg” tõlgitud sõna-sõnalt Kus mitte; samuti on väljend vnd bittet vmb Friede tõlgitud ninck pallut rahwo perrast. Versioonis „Pil lõpp” on aru saada, et Kuii aggas mitte lähtub käsikirjast „Pil alg”, ninck pallup Rahwo aga WT 1686 tekstist.

Tabel 4. Lk 14,32

\begin{tabular}{|c|c|c|c|c|}
\hline Pil alg & Pil lõpp & WT 1686 & Lu 1670 & Blaeu 1633 \\
\hline $\begin{array}{l}32 . \underline{\text { Kus }} \\
\text { mitte, sihß } \\
\text { leckitat } \\
\text { Temma } \\
\text { keßut welja, } \\
\text { kus se Toine } \\
\text { wehl } \\
\text { kaugkel on, } \\
\text { ninck pallut } \\
\underline{\underline{\text { rahwo }}} \\
\text { perrast. }\end{array}$ & $\begin{array}{l}32 . \underline{\underline{\text { Kuii }}} \\
\underline{\text { aggas mitte}} \\
\text { sihß leckitap } \\
\text { Temma } \\
\text { keßut, kus } \\
\text { Toine weel } \\
\text { kaugkel on, } \\
\text { ninck pallup } \\
\underline{\text { Rahwo. }}\end{array}$ & $\begin{array}{l}\text { 32. Ent kui } \\
\text { temmä ei } \\
\text { jouwwa/ sis } \\
\text { lähätab } \\
\text { temmä } \\
\text { Käsku/ kui } \\
\text { se töine weel } \\
\text { kawwen om/ } \\
\underline{\text { nink palleb }} \\
\underline{\text { Rauwo. }}\end{array}$ & $\begin{array}{l}32 . \underline{\underline{\text { Wo }}} \\
\text { nicht/ so } \\
\text { schicket er } \\
\text { Botschafft/ } \\
\text { wenn jener } \\
\text { noch ferne } \\
\text { ist/ } \underline{\text { und }} \\
\underline{\text { bittet umb }} \\
\underline{\underline{\text { Friede. }}}\end{array}$ & 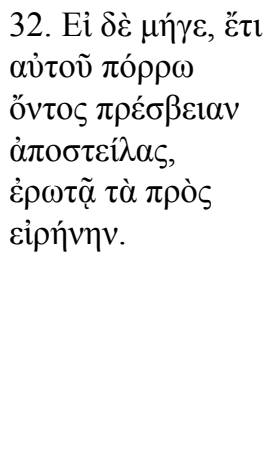 \\
\hline
\end{tabular}

Lk 14,34 (tabel 5) on väljend DAs Saltz ist ein gut Ding käsikirjas „Pil alg” tõlgitud otse Se Sohle on $\ddot{u}[x]$ heh Aßi. WT 1686-s on sama väljend tõlgitud sarnasemalt kreeka tekstiga Sohl om häh, sealt ka versioonis „Pil lõpp” Sohl on heh.

Tabel 5. Lk 14,34

\begin{tabular}{|c|c|c|c|c|}
\hline Pil alg & Pil lõpp & WT 1686 & Lu 1670 & Blaeu 1633 \\
\hline $\begin{array}{l}\text { 34. Se Sohle } \\
\text { on ü[x] heh } \\
\underline{\text { Aßi }, \text { kus }} \\
\text { Temma } \\
\text { agkas Tuim, } \\
\text { mis kaas } \\
\text { peap sohlatut } \\
\text { sahma. }\end{array}$ & $\begin{array}{l}\text { 34. Sohl on } \\
\text { heh, kus } \\
\text { Temma agkas } \\
\text { tuimax } \\
\text { sahnut, kuß } \\
\text { kaa peap } \\
\text { sohlatut } \\
\text { sahma. } \\
\text { kuhlko. }\end{array}$ & $\begin{array}{l}\text { 34. Sohl om } \\
\text { häh: Ent kui } \\
\text { Sohl tuimatz } \\
\text { lät/ mink ka } \\
\text { es sedda } \\
\text { jälle hähtz } \\
\text { tettä? }\end{array}$ & $\begin{array}{l}\text { 34. DAs Saltz } \\
\text { ist ein gut } \\
\underline{\text { Ding/ wo aber }} \\
\text { das Saltz } \\
\text { thumb wird/ } \\
\text { womit wird } \\
\text { man würtzen? }\end{array}$ & 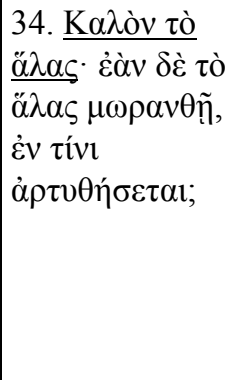 \\
\hline
\end{tabular}


Lk 14,35 (tabel 6) puhul võib käsikirjas „Pil alg” näha, et raskusi on valmistanud eituste tõlkimine. Saksakeelne ei ... ega eitust sisaldav tekst Es ist weder auff das Land/ noch in den Mist nütz on tõlgitud jaatavaks: Temma kölbap echk mahl echk Sittal. Käsikirjas „Pil lõpp” olev Sep ep kölba ep Mah ep ka Sitta siße langeb kokku WT 1686 sõnastusega.

Tabel 6. Lk 14,35

\begin{tabular}{|c|c|c|c|c|}
\hline Pil alg & Pil lõpp & WT 1686 & Lu 1670 & Blaeu 1633 \\
\hline $\begin{array}{l}\text { 35. Temma } \\
\text { kölbap echk } \\
\text { mahl echk } \\
\text { Sittal, } \\
\text { erranis } \\
\text { Temma } \\
\text { heitetaße } \\
\text { erra. Kennel } \\
\text { korwat } \\
\text { ommat, } \\
\text { Temma } \\
\text { kuhlko. }\end{array}$ & $\begin{array}{l}\text { 35. Sep ep } \\
\text { kölba ep } \\
\text { Mah ep ka } \\
\text { Sitta siße, } \\
\text { erranis } \\
\text { Tedda } \\
\text { heitetaxe } \\
\text { erra. Kennel } \\
\text { korwat } \\
\text { ommat } \\
\text { kuhlda, se } \\
\text { kuhlko. }\end{array}$ & $\begin{array}{l}\begin{array}{l}35 . \text { Se ei } \\
\text { kölba sis }\end{array} \\
\text { Maha/ ei kah } \\
\text { Sitta sisse: } \\
\text { (Enge) } \\
\text { nemmä } \\
\text { heitwa sedda } \\
\text { erra. Kel } \\
\text { Körwu on } \\
\text { kuhlda/ se } \\
\text { kuhlge. }\end{array}$ & $\begin{array}{l}\text { 35. Es ist } \\
\text { weder auff } \\
\text { das Land/ } \\
\text { noch in den } \\
\text { Mist nütz/ } \\
\text { sondern } \\
\text { man wirds } \\
\text { wegwerffe. } \\
\text { wer Ohren } \\
\text { hat zu } \\
\text { hören/ der } \\
\text { höre. }\end{array}$ & 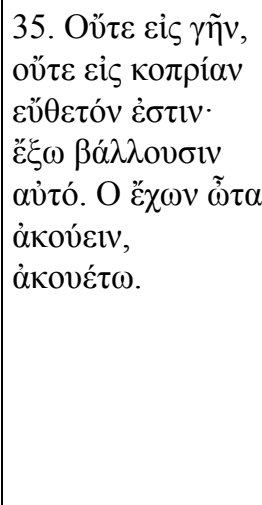 \\
\hline
\end{tabular}

Tabelist 7 võib leida kinnitust, et Lk 14,27 teksti lisaeitus ninck münno ierrel ep kei käsikirjas „Pil lõpp” pärineb WT 1686-st. Ühtlasi kajastab käsikiri „Pil alg” tõlkija(te) otsust arvestada aja jooksul kujunenud arusaamade muutust, mille kohaselt ei tähenda risti kandmine enam surmavalmidust, vaid lihtsalt inimese elu viletsust.

Tabel 7. Lk 14,27

\begin{tabular}{|c|c|c|c|c|}
\hline Pil alg & Pil lõpp & WT 1686 & Lu 1670 & Blaeu 1633 \\
\hline $\begin{array}{l}27 . \text { Ninck ke } \\
\text { mitte omma } \\
\text { willizuße } \\
\text { kandap, ninck } \\
\text { münno ierrel } \\
\text { keit, Temma } \\
\text { woip mitte } \\
\text { münno } \\
\text { Sullane olla. }\end{array}$ & $\begin{array}{l}\text { 27. Ninck ke } \\
\text { omma Riste } \\
\text { ep kanda, } \\
\text { ninck münno } \\
\underline{\text { ierrel ep kei, }} \\
\begin{array}{l}\text { Se ep woi } \\
\text { mitte münno } \\
\text { jünger olla. }\end{array}\end{array}$ & $\begin{array}{l}\text { 27. Nink kä } \\
\text { omma Risti } \\
\text { ei kanna/ } \\
\text { nink ei tulle } \\
\underline{\underline{\text { minno perrä/ }}} \\
\begin{array}{l}\text { se ei woi } \\
\text { minno } \\
\text { Jünger olla. }\end{array}\end{array}$ & $\begin{array}{l}\text { 27. Und wer } \\
\text { nicht sein } \\
\text { Creutz } \\
\text { träget/ und } \\
\text { mir } \\
\text { nachfolget/ } \\
\text { der kan nicht } \\
\text { mein Jünger } \\
\text { seyn. }\end{array}$ & 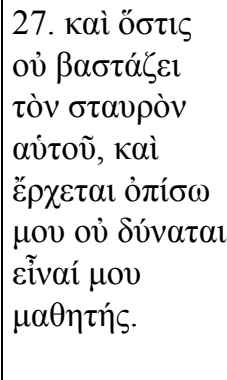 \\
\hline
\end{tabular}




\section{Raskused eituste tõlkimisel}

Lk 14,27 ei ole ainus näide eituste ekslikust eesti keelde tõlkimisest. Pigem olid eitused tõlkijatele üldiseks probleemiks. Et nende olukorda paremini mõista, on siin kohane meenutada, et saksa eituskonstruktsioonid on eesti omadest erinevad, mistõttu nende eesti keelde tõlkimine on üpris keerukas ettevõtmine ja nõuab eestipärase tulemuse saamiseks lause struktuuri märkimisväärset muutmist (Penjam 2011: 13-14). Eituste tõlkimise probleemidele XVII sajandi lõpus juhib tähelepanu ka Kai Tafenau (Tafenau 2011b: 138-139). Lisan omalt poolt mõned näited Luuka evangeeliumist.

Tabelis 8 on näide Lk 8,16 saksakeelse eitava pronoomeni Niemand tõlkimise kohta. Pronoomeni niemand kasutus ei näita üksnes seda, et osutatud mitte keegi ei tee ainult üht järgnevat tegevust, vaid ta ei tee mitte ainsatki järgnevas loetelus toodud tegevustest. Niisuguse mõtte edasiandmiseks tuleks eesti keeles kasutada korduvat eitust. See tähendab, et subjekti eitus (eitav pronoomen subjektina) peaks korduma ka predikaadi eitusena. Nii võiks tõlkida, et Mitte keegi või Ükski ei süüta küünalt ega kata teda astjaga kinni ega pane seda sängi alla. Alles vastandav sidesõna Sondern = erranis/ Enge/ Waid lõpetab sellise eituste jada. Nt P 1997-s on sama salm väga sobivalt tõlgitud kõrvallause ja kahe eituse abil: „Aga ükski, kes on süüdanud lambi, ei kata seda astjaga kinni ega pane voodi alla, vaid paneb selle lambijalale, et tuppa astujad näeksid valgust." Käsikirjas „Pil alg” on aga saksa keele eeskujul eitust väljendatud ainult pronoomeniga Ep üxkit. Võimalik, et käsikirjas „Pil lõpp” on püütud sõnade järjekorra vahetamisega üxkit Ep eitust predikaadiga siduda. Seejuures jääb siiski segama eitussõnale järgnev modaaladverb aggas. Eesti keele kohaselt on WT 1686-s ja selle eeskujul ka UT 1715-s esimene predikaat tõlgitud vastavalt keake ei leüdä ja ükski ei süttita. Loetelu järgmised predikaadid on aga ilma eituseta: kattab sedda Annumaga kinni/ echk pannneb sedda Sängi alla ja kattab tedda Astjaga kinni/ ehk panne-b tedda Sänge alla. 
Tabel 8. Lk 8,16

\begin{tabular}{|c|c|c|c|c|}
\hline Lu 1670 & Pil alg & Pil lõpp & WT 1686 & UT 1715 \\
\hline $\begin{array}{l}\text { Niemand aber } \\
\text { zündet ein } \\
\text { Liecht an / } \\
\text { und bedeckts } \\
\text { mit einem } \\
\text { Gefäsz/ oder } \\
\text { setzts unter } \\
\text { eine Banck/ } \\
\text { sondern er } \\
\text { setzts auff } \\
\text { einen } \\
\text { Leuchter/ } \\
\text { auff dasz/ } \\
\text { wer hinein } \\
\text { gehet/ das } \\
\text { Liecht sehe/ }\end{array}$ & $\begin{array}{l}\underline{\text { Ep üxkit }} \\
\text { aggas süttitap } \\
\text { Kühnla, nink } \\
\text { kattap sedda } \\
\text { Astja ka, } \\
\text { echk pannep } \\
\text { sedda ühhe } \\
\text { Penki alla, } \\
\text { erranis } \\
\text { temma } \\
\text { pannep sedda } \\
\text { ühhe Lüchtri } \\
\text { pehle, eth. ke } \\
\text { sisse lehhep, } \\
\text { sedda } \\
\text { nechko. }\end{array}$ & 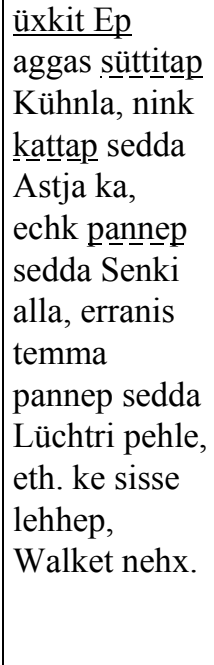 & $\begin{array}{l}\text { Ent keake ei } \\
\text { leüdä } \\
\text { Kühnalt/ nink } \\
\text { kattab sedda } \\
\text { Annumaga } \\
\text { kinni/ echk } \\
\text { pann-_eb sedda } \\
\text { Sängi alla: } \\
\text { Enge temmä } \\
\text { panneb tedda } \\
\text { Kühnla Jalla } \\
\text { pähle/ et ne/ } \\
\text { kumma sisse } \\
\text { lähwa/ sedda } \\
\text { Walget } \\
\text { näggewa. }\end{array}$ & $\begin{array}{l}\text { Agga ükski ei } \\
\text { süttita Künalt/ } \\
\text { ja kattab } \\
\text { tedda Astjaga } \\
\text { kinni/ ehk } \\
\text { panne-_b tedda } \\
\text { Sänge alla: } \\
\text { Waid panneb } \\
\text { tedda Küünla- } \\
\text { Jalla päle/ et } \\
\text { need/ ke sisse } \\
\text { tullewad/ } \\
\text { Walget } \\
\text { näwad. }\end{array}$ \\
\hline
\end{tabular}

Kui viimati käsitletud kirjakohas on WT 1686 tõlge jätnud kaks verbi ekslikult ilma eituseta, siis eespool vaadeldud kirjakohas Lk 14,27 (vt tabel 7) on üks eitus ekslikult rohkem.

Lk 8,27 (tabel 9) on käsikirjas „Pil alg” tõlgitud otse saksa keelest: pannis mitte Rihdet ümber, ... jej mitte Kodda sees. Eesti keeles oleks kohane eitada verbi, nii nagu seda on tehtud WT 1686-s: temmä es peä mitte Reiwast Säljan/nink es püssi Majan ning WT 1686 eeskujul ka käsikirjas „Pil lõpp”: ep pannut Rihdet Selga, nink ep jent ühteke Kotta, samuti UT 1715-s: temma ei piddanud Riet Seljas/ ja ei seisnud Koddu. 
Tabel 9. Lk 8,27

\begin{tabular}{|c|c|c|c|c|}
\hline Lu 1670 & Pil alg & Pil lõpp & WT 1686 & UT 1715 \\
\hline $\begin{array}{l}\text { Und als er } \\
\text { austrat auff } \\
\text { das Laud/ } \\
\text { begegnet ihm } \\
\text { ein Mann aus } \\
\text { der Stadt/ der } \\
\text { hatte Teuffel/ } \\
\text { von langer } \\
\text { Zeit her/ und } \\
\text { thät keine } \\
\underline{\underline{\text { Kleider an/ }}} \\
\text { und bleib in } \\
\underline{\text { keinem }} \\
\underline{\underline{\text { Hause/ }}} \\
\text { sondern in } \\
\text { den Gräbern. }\end{array}$ & $\begin{array}{l}\text { Nink kuß } \\
\text { temma } \\
\text { weljaastis } \\
\text { Mahle, tulli } \\
\text { temma wasto } \\
\text { üx Mees } \\
\text { Lidna seest, } \\
\text { sel ollit } \\
\text { Kurratit } \\
\text { kauwa Ajast } \\
\text { sahto, nink } \\
\text { pannis mitte } \\
\underline{\text { Rihdet ümber, }} \\
\text { nink jej mitte } \\
\underline{\text { Kodda sees, }} \\
\text { erraniß } \\
\text { Haudade sees. }\end{array}$ & $\begin{array}{l}\text { Nink kuß } \\
\text { temma } \\
\text { weljaastis } \\
\text { Mahle, tulli } \\
\text { temma wasto } \\
\text { üx Mees } \\
\text { Linnast, sel } \\
\text { ollit Kurratit } \\
\text { ammo Ajast, } \\
\text { nink ep } \\
\text { pannut Rihdet } \\
\text { Selga, nink ep } \\
\text { jent ühteke } \\
\text { Kotta, erraniß } \\
\text { Haudade sees. }\end{array}$ & $\begin{array}{l}\text { Nink kui } \\
\text { temmä wälja } \\
\text { Mahle lätz/ } \\
\text { sis tulli ütz } \\
\text { Mehs Libnast } \\
\text { temmä wasta/ } \\
\text { kel Kurratid } \\
\text { olli olnu } \\
\text { ammust } \\
\text { sahni/ nink } \\
\text { temmä es peä } \\
\text { mitte Reiwast } \\
\text { Säljan/ nink } \\
\text { es püssi } \\
\text { Majan/ enge } \\
\text { Haudun. }\end{array}$ & $\begin{array}{l}\text { Agga kui } \\
\text { temma Male } \\
\text { läks/ tulli } \\
\text { temma } \\
\text { wasto üks } \\
\text { Mees } \\
\text { Linnast/ sel } \\
\text { ollid kurjad } \\
\text { Waimud } \\
\text { ammo } \\
\text { Ajast/ ja } \\
\text { temma ei } \\
\text { piddanud } \\
\text { Riet Seljas/ } \\
\text { ja ei seisnud } \\
\text { Koddu/ kuid } \\
\text { Hauade } \\
\text { sees. }\end{array}$ \\
\hline
\end{tabular}

Lk 12,2 (tabel 10) on näide sellest, kuidas käsikirjas „Pil lõpp” on küll parandatud esimese osalause sõnastust, kuid Pilistvere käsikirja mõlemas, nii alg- kui ka lõppversioonis on eituse tõlge jäänud saksapäraseks. Sobiv eituse tõlge on WT 1686, samuti UT 1715 tekstis. Viimases on selguse mõttes korratud fraasi ühtige ep olle.

Tabel 10. Lk 12,2

\begin{tabular}{|c|c|c|c|c|}
\hline Lu 1670 & Pil alg & Pil lõpp & WT 1686 & UT 1715 \\
\hline $\begin{array}{l}\text { Es ist aber } \\
\text { nichts } \\
\text { verborgen/ } \\
\text { das nicht } \\
\text { offenbar } \\
\text { werde/ noch } \\
\text { heimlich/ das } \\
\text { man nicht } \\
\text { wissen } \\
\text { werde. }\end{array}$ & $\begin{array}{l}\text { Üchtekit } \\
\text { aggas peitetut } \\
\text { on, mea mitte } \\
\text { ilmotaxe, } \\
\text { ninck sallaja } \\
\text { mea mitte } \\
\text { teeda annaxe. }\end{array}$ & $\begin{array}{l}\text { Middakit } \\
\text { aggas on } \\
\text { errepeetut, } \\
\text { mea mitte } \\
\text { awwalikkux } \\
\text { sahx ech } \\
\text { sallaja mea } \\
\text { mitte tehda } \\
\text { sahx. }\end{array}$ & $\begin{array}{l}\text { Ent middäke } \\
\text { ei olle kinni } \\
\text { kattetu/ mes } \\
\text { awwalikkusz } \\
\text { ei sah: Nink } \\
\text { errapeedetu/ } \\
\text { mes teeda ei } \\
\text { sah. }\end{array}$ & $\begin{array}{l}\text { Agga ühtige } \\
\text { ep olle } \\
\text { kinnikaetud/ } \\
\text { mis ei peaks } \\
\text { ilmoma: Ja } \\
\text { ühtige e ep p olle } \\
\text { ärrapeidetud/ } \\
\text { mis ei peaks } \\
\text { täda sama. }\end{array}$ \\
\hline
\end{tabular}


Pöördugem nüüd tagasi Lk 14,27 juurde (vt tabel 7). Saksakeelses tõlkes on siin eitatud risti kandmise tegevust: Und wer nicht sein Creutz träget. Võimalik, et Virginiuste arvates laienes eitus rinnastava sidesõna vnd vahendusel ka järgneva osalause predikaadile und mir nachfolget (subjekt wer on ju sama), nii nagu see on kirjakohas Lk 14,26 (vt tabel 2), kus eitus und hasset nicht hõlmab kogu järgneva objektide loetelu Vatter/Mutter/Weib/Kind/Brüder/Schwester/auch darzu sein eigen Leben, ja seepärast tõlgiti nii, nagu ise tekstist aru saadi: Nink kä omma Risti ei kanna/ nink ei tulle minno perrä. Nende kahe lause juures on oluline erinevus see, et Lk 14,26 on esimene osalause jaatav ning eitus järgneb alles teises osalauses, Lk 14,27 on aga eitatud juba esimest osalauset. See võiski põhjustada raskuse kogu lause mõistmisel. Ilmselt poleks niisugust probleemi tekkinud, kui Lk 14,27 osalausete järjekord oleks olnud vastupidine: kes minu järel käib ja oma risti ei kanna, see ei või olla minu jünger.

\section{Kokkuvõte}

Artiklis on uuritud omavahel pärimuslikult sõltuvate Mt 10,38 ja Lk 14,27 tekstide eituste tõlkimist. Tegemist on näitega sellest, kuidas mingi tõlkeviga võib hilisematest redigeerimistest ja osalt uuesti tõlkimisest hoolimata jääda püsima ning kinnistuda lausa sajanditeks.

Vaadeldud kirjakohad sisaldavad Jeesuse ütlust, mis koosneb kolmest osalausest. Neist esimene ja viimane on eitavad, kuid eestikeelses tõlkes on eitus ka teises osalauses. Selline lisaeitus leidub juba Virginiuste tõlgitud ja 1686. aastal trükitud „Wastses Testamendis”. Samuti on see säilinud 1715. aastal välja antud põhjaeestikeelses Uues Testamendis. Uue Testamendi esimesed eestikeelsed tõlked pärinevad saksa soost pastoritelt, kellel oli raskusi eituste edasiandmisega teistsuguse lausestruktuuriga eesti keeles. Kasutades aastatest 1680-1705 pärit Luuka evangeeliumi tõlgete käsikirjade trükis avaldatud tekste, on artiklis vaatluse alla võetud valik eitusi sisaldavaid salme. Need näited lubavad oletada, et nii Mt 10,38 kui ka Lk 14,27 lisaeituse puhul on tegemist tõlkeeksitusega. Seejuures ei saa välistada võimalust, et tõlkijad pidasid silmas tollastes tekstides sagedase stiilivõttena kasutusel olnud parallelismi.

Uue Testamendi põhjaeesti keelde tõlkimisel oli tähenduslik koht nii 1686. aasta Liepa (Lindenhofi) kui ka 1687. aasta Pilistvere piiblikonverentsil. Suure tõenäosusega oli Pilistveres toimetamisele tulnud tekst Heinrich Göseken vanema käsikirja ärakiri, mida ümberkirjutaja oli kohati täiendanud-parandanud ja ühtlustanud. Selles käsikirjas vastab Lk 14,27 tõlge algtekstile - lisaeitust seal ei olnud. Küll esineb 
aga lisaeitus Pilistvere redigeeritud käsikirjas. Kahtlemata on siin näha WT 1686 mõju, millele on aidanud kaasa ka Adrian Virginiuse osalemine piiblikonverentsidel.

\author{
Aadress: \\ Peeter Roosimaa \\ Tartu Ülikool \\ Usuteaduskond \\ Ülikooli 18, 51014 Tartu \\ E-post: Peeter.Roosimaa@ut.ee
}

\title{
Allikad
}

Blaeu 1633 = THS KAINHS DIAQHKHS APANTA. Amsterdami: Apud Guiljelmum Blaeu, 1633.

Nestle-Aland ${ }^{27} 1993$ = Novum Testamentum Graece post Eberhard Nestle et Erwin Nestle editione vicesima septima revisa communiter ediderunt Barbara et Kurt Aland, Johannes Karavidopoulos, Carlo M. Martini, Bruce M. Metzger. Apparatum criticum novis curis elaboravarerunt Barbara et Kurt Aland una cum Institutio Studiorum Textus Novi Testamenti Monasterii Westphaliae. 27. revidierte Aufl. Stuttgart: Deutsche Bibelgesellschaft.

Lu 1670 = Biblia, Das ist, die gantze H. Schrifft, Alte und Neues Testaments teutsch, D. Mart. Luthers ... Von etlichen reinen Theologen, demeigentlichen Wortverstand nach, erkläret ... Darbey auch über die sonst gewöhnliche, jetzt aber von neuem corrigirte und wol verbesserte Biblische Register, unter andern zu finden ein Bericht ... - Nürnberg: Gedruckt und verlegt durch Christoph Endtern. Im Jahr Christi M.DC.LXX.

WT 1686 = Meije Jssanda JEsusse Kristusse Wastne Testament Echk Jummala Pöhä Sönna Kumb Perräst Jssanda JEsusse Kristusse Sündmist pöhist Ewangelistist nink Apostlist om ülleskirjotetu. Cum Gratia et Privilegio S. R. M. Sueciae. RIGA. Gedruckt durch Johann Georg Milcken Königl. Buchdr. Im Jahr MDCLXXXVI.

UT 1715 = Meie Issanda Jesusse Kristusse Uus Testament Ehk Jummala Ue Sädusse Sanna Mis Pärrast Issanda Jesusse Kristusse Sündmist pühhast Ewangelistist ja Apostlist on ülleskirjotud/ ja nü̈d Ma Kelel üllespantud Tallinnas. TALLINNAS Trükkis Johan Kristow Prendeken Aastal 1715.

UT 1912 = Meie Issanda Jeesuse Kristuse Uus Testament ehk Uue Seaduse Raamat ja Kuninga Taaweti Laulu=Raamat. Trükitud A. Mickwitz'i trükikojas. Proowitrükk, Tallinn.

SP 1939 = Jumala Püha Sõna Suur Piibel. Wälja antud eestikeelse piibli 200 aasta juubeli tähistamiseks. Sisaldab Wana ja Uue Testamendi ning Apokriiwa raama- 
tud. Kaunististena 226 grawüüri G. Doré'lt ja wärwipilte teistelt suurmeistritelt. Keeleliseks aluseks eestikeelse piibli 15. trükk. Tartu. Tallinn: Loodus.

P 1968 = Piibel. Vana ja Uus Testament. London: The British and Foreign Bible Society.

UT 1989 = Uus Testament ja Psalmid ehk Vana Testamendi laulud. Tallinn: EELK Konsistoorium.

P 1997 = Piibel. Vana ja Uus Testament. Tallinn: Eesti Piibliselts.

\section{Kirjandus}

Barklay, William (1968) Lukasevangelium. (Auslegung des Neuen Testaments.) Wuppertal: Aussaat Verlag GmbH.

Bärenson, Jaan (1998) „Ühise töö tulemus”. Eesti Kirik. Eesti Kirikute Nõukogu vaheleht. 27. mai.

Grundmann, Walter (1975) Das Evangelium nach Matthäus. 4. Aufl. (Theologischer Handkommentar zum Neuen Testament.) Berlin: Evangelische Verlagsanstalt.

Paul, Toomas (1999) Eesti piiblitõlke ajalugu. Esimestest katsetest kuni 1999. aastani. (Eesti Teaduste Akadeemia Emakeele Seltsi toimetised, 72.) Tallinn: Emakeele Selts.

Penjam, Pille (2011) „Eituskonstruktsioonid eesti vanemas kirjakeeles”. Oma Keel 22, 12-17. Saadaval internetis

$<$ http://www.emakeeleselts.ee/omakeel/2011_1/OK_2011-1_02.pdf $>$. Vaadatud 15.08.2013.

Reila, Heiki (2007) „Uue Testamendi Hornungi tõlke kohast vaimuliku eesti keele kujunemisloos". Keel ja Kirjandus 2, 143-151.

Reiser, Marius (2001) Sprache und litarische Formen des Neuen Testaments. Eine Einführung. Paderborn, München, Wien, Zürich: Ferdinand Schöningh.

Roosimaa, Peeter (2003) „,Wastne Testament” - das erste estnischsprachige Neue Testament". Die Bedeutung der Religion für Gesellschaften in Vergangenheit und Gegenwart: Akten des fünften gemeinsamen Symposiums der EvangelischTheologischen Fakultät der Universität Tartu, der Estnischen Studiengesellschaft für Morgenlandkunde und der Deutschen Religionsgeschichtlichen Studiengesellschaft am 2. und 3. November 2001 zu Tartu/Estland, 171-186. Manfried L. G. Dietrich, Tarmo Kulmar, Hg. (FARG, 36.) Münster: Ugarit-Verlag.

Roosimaa, Peeter (2004) Uue Testamendi eestikeelsetest tõlgetest ja tõlkimist toetavast eksegeesist. (Dissertationes theologiae Universitatis Tartuensis, 7.) Tartu: Tartu Ülikool.

Ross, Kristiina (koostaja) (2007) Põhjaeestikeelsed Uue Testamendi tõlked 16801705: Luuka evangeelium. Apostlite teod. Tallinn: Eesti Keele Sihtasutus.

Schlatter, Adolf (1979) Die Evangelien nach Markus und Lukas. (Erläuterungen zum Neuen Testament, 2.) Stuttgart: Calwer Verlag. 
Schweizer, Eduard (1981) Das Evangelium nach Matthäus. (NTD, 2.) Göttingen: Vandenhoeck \& Ruprecht.

Tafenau, Kai (2006) „Eestikeelsetest Uue Testamendi tõlkekäsikirjadest Ajalooarhiivis". Läänemere provintside arenguperspektiivid Rootsi suurriigis 16/17. sajandil 2, 241-294. Koostanud Enn Küng. (Eesti Ajalooarhiivi toimetised, 12 (19).) Tartu: Eesti Ajalooarhiiv.

Tafenau, Kai (2009) „Adrian Virginiuse eluloost”. Keel ja Kirjandus 11, 847-855.

Tafenau, Kai (2011a) „Et tõlkida piiblit eesti ja läti keelde...”. Tuna 14, 1, 41-59.

Tafenau, Kai (2011b) „Diskussionen über die estnische Schriftsprache in der zweiten Hälfte des 17. Jahrhunderts: Argumente und Beispiele". Linguistica Uralica 47, 2, $130-143$.

Tafenau, Kai (2011c) Uue Testamendi tõlkimisest Rootsi ajal: käsikirjad, tõlkijad ja eesti kirjakeel. (Dissertationes philologiae estonicae Universitas Tartuensis, 27.) Tartu: Tartu Ülikooli Kirjastus.

\begin{abstract}
Peeter Roosimaa: For centuries remained questionable translation of Matthew 10:38 and Luke 14:27. Current article deals with the problems in translating New Testament into Estonian language. In parallel passages Mathew 10:38 and Luke 14:27 there is a saying of Jesus that consists of two conditions and one statement. First condition is negation, second condition is affirmation and conclusion is once again negation. In Estonian translation both conditions are negations. This extra negation is found already in "Wastne Testament" that was published in year 1686. The first translations of New Testament were created by German origin pastors who had trouble with different rules of negation in Estonian language. Print published manuscripts of Gospel of Luke's translations from 1680-1705 were used for composing this article. This article suggests that additional negation in translation of Mathew 10:38 and Luke 14:27 is translation mistake that remained unnoticed during later revisions and partial retranslation.
\end{abstract}

Keywords: New Testament, Bible translation, translating negation, Pilistvere manuscripts 